Área Abierta. Revista de comunicación

audiovisual y publicitaria

ISSN: 2530-7592

\title{
Características formales de las plataformas de peticiones online: sistemas públicos anglosajones, la opción privada en España
}

\author{
Dafne Calvo Miguel ${ }^{1}$
}

Recibido: 2 de marzo de 2016 / Aceptado: 17 de mayo de 2016

Resumen. Las peticiones, que pueden definirse como demandas hacia instituciones gubernamentales concretas firmadas por los ciudadanos, han desarrollado en Internet nuevas posibilidades en relación al feedback con las Administraciones, la comodidad y flexibilidad o el ahorro económico, entre otros (Juris, 2005). En países esencialmente anglosajones se han desarrollado plataformas que canalicen esta forma de participación, como es el caso del Parlamento Escocés, el Bundestag Alemán, o los municipios noruegos (Lindner \& Riehm, 2011). Sin embargo, en España este tipo de iniciativas se han gestionado a través de alternativas privadas. El objetivo del presente trabajo es explorar la relación entre una de estas webs, Change.org, a fin de definir su funcionamiento y confrontar los rasgos formales de cada uno de los modelos. Para alcanzar estos objetivos, realizamos un análisis de contenido cualitativo del sitio web de Change.org, y así analizar el procedimiento para crear y firmar peticiones, los foros de discusión, la estructura de la página principal y las posibilidades del usuario para contactar con los miembros de la página. Los datos del trabajo de campo muestran resultados diversos sobre Change respecto a las plataformas públicas de e-petitions. Así, la web de peticiones destaca por su diseño simple y la aportación de instrucciones y guías de uso que facilitan la participación sencilla y rápida por parte de los usuarios. Sin embargo, los escasos espacios de deliberación y las posibilidades de contacto con el equipo y usuarios de Change.org alejan a la página de un modelo público de recogida de firmas online. Palabras clave: change.org; e-petitions; usabilidad; ambiente deliberativo; feedback

\section{[en] Formal Aspects of Online Petition Platforms: Anglos Public Systems and Private Option in Spain}

\begin{abstract}
Petitions can be defined as specific demands on government institutions signed by citizens. On the Internet, this kind of participation has developed new possibilities in relation with the administration feedback, accessibility and flexibility or cost savings, for example (Juris, 2005). In essentially AngloSaxon countries, political powers have developed platforms to manage this form of participation, such as the Scottish Parliament, the Bundestag, or Norwegian municipalities (Lindner \& Riehm, 2011). However, in Spain these initiatives have had to be channeled through private alternatives. The aim of this paper is to explore the relationship between Change.org, which is one of these sites, to define its operation and confront the formal features of each of the models. To achieve these goals, we performed a qualitative content analysis of the website of Change.org. We analyze the process of creating and signing petitions, the discussion forums, the structure of the home page and the user possibilities to contact the members of the page. The results of the field work show different results on Change
\end{abstract}

\footnotetext{
1 Universidad de Valladolid (España)

E-mail: dafnecal@gmail.com
} 
regarding public platforms of e-petitions. Thus, this tool for petitions noted for its simple design and its instructions and user guides that facilitate quick and easy participation by users. However, limited spaces of deliberation and scanty possibilities of contact with Change.org team and users distance the page to a public model of online petitions.

Keywords: change.org; e-petitions; Usability; Deliberative Context; Feedback

Sumario. 1. Introducción. 2. Características de las plataformas de peticiones online. 3. Metodología. 4. Resultados. 5. Discusión de los resultados y conclusiones. 6. Bibliografía

Cómo citar: Calvo Miguel, D. (2017) Características formales de las plataformas de peticiones online: sistemas públicos anglosajones, la opción privada en España, en Área Abierta. Revista de comunicación audiovisual y publicitaria 17 (2), 241-258. http://dx.doi.org/10.5209/ARAB.51992

\section{Introducción}

El estudio de las peticiones creadas y gestionadas por la sociedad civil se ha focalizado, en buena medida, en una serie de prácticas que Juris (2005) atribuyó a las herramientas digitales en general y que disponen a la ciudadanía para emprender las diferentes formas de acción política colectiva: la creación de vínculos horizontales y de conexiones entre perfiles con autonomía; la circulación libre y abierta de información; la colaboración mediante una coordinación descentralizada; la toma de decisiones directa y democrática y, por último, la creación de redes auto-dirigidas.

Unos estudios, por tanto, que entroncan con el debate académico más reciente sobre las TIC, que no enfatiza en el uso de las herramientas digitales, sino en la forma en que dichas plataformas son de valor para una mejora de la representación ciudadana en los sistemas democráticos (Campos-Domínguez, 2014). Las cualidades analizadas son, entre otras, el grado de comodidad y flexibilidad, interactividad mejorada, interfaz para el anonimato, pretextos normativos, feedback y deliberación (Tomkova, 2009).

En este contexto, las peticiones son demandas hacia instituciones gubernamentales por parte de ciudadanos que las firman para posicionarse sobre preocupaciones de la agenda política del momento (Diaz et al., 2009; Cruickshank et al. 2010, Lindner $\&$ Riehm, 2011). Con frecuencia se ha apuntado a un beneficio relevante para las Administraciones públicas que han desarrollado infraestructuras para dar cabida a las peticiones electrónicas, como es la reducción de la inversión económica producida por las iniciativas en papel (Lindner \& Riehm, 2011).

Sin embargo, y a diferencia de otros países esencialmente europeos (Lindner \& Riehm, 2009), en España no existen plataformas públicas de petición electrónica, por lo que esta forma de participación se canaliza a través de webs como Change.org. En este trabajo estudiaremos de qué forma esta alternativa es capaz de completar el vacío del Estado en materia de participación y qué limitaciones tiene respecto a las propuestas gubernamentales que se han desarrollado fuera del territorio nacional. 


\section{Características de las plataformas de peticiones online}

Ya en los años noventa, Davis (1999) reconocía que la tecnología provista por la Red podría permitir a sus usuarios entablar comunicaciones con quienes toman las decisiones institucionales, pudiendo debatir públicamente con ellos. En este caso particular, el feedback entre la plataforma y el ciudadano se refiere tanto a la posibilidad de seguir el proceso de la petición como al contacto directo con las instituciones públicas para conocer sus resultados, lo que facilita el compromiso cívico de los ciudadanos si consideran que su acción política obtendrá una respuesta por parte de las instituciones públicas, tal como coinciden un número amplio de autores (Cruickshank \& Smith, 2009; Tomkova, 2009). Un hecho, además, que resulta de relevancia cuando la implantación de este tipo de iniciativas responde a la voluntad de las instituciones públicas por encontrar legitimación frente a sus electores (Lindner \& Riehm, 2011).

La transparencia en las directrices del proceso desde que se presenta la petición hasta que obtiene una respuesta, por tanto, es esencial en el caso de esta forma de participación (Whyte et al., 2005), máxime cuando, como herramientas digitales, tienen las posibilidades técnicas necesarias para ofrecer información sobre los antecedentes de un asunto político concreto, sobre el status actual de la petición y sobre una propuesta iniciada en la plataforma.

Bajo esta premisa, las instituciones han desarrollado diversas formas de mantener a los interesados informados sobre el desarrollo de las e-petitions que han apoyado o presentado, pues estas funcionan más efectivamente cuando existe un diálogo fluido entre los ciudadanos y los miembros electos de las instituciones públicas (Cruickshank et al., 2010).

En Queensland, por ejemplo, se ofrece la posibilidad de añadir la dirección de correo electrónico para que los firmantes puedan recibir las respuestas ministeriales sobre la petición concreta. Esta, además, es necesariamente introducida al Parlamento por un miembro de la Cámara, por lo que el peticionario cuenta con un mecenas (sponsor) que está de acuerdo con la iniciativa y que se compromete a que esta se presente formalmente y se responda (Lindner \& Riehm, 2011).

Cuando esto sucede, se envían correos electrónicos a los firmantes, con enlaces a la página donde se publica la respuesta, así como con información adicional y detallada sobre el proceso. Si, por el contrario, la petición no obtiene respuesta en seis meses, un email insta a los interesados a visitar el sitio web en futuras ocasiones (Finnimore, 2008). En el ámbito de la sociedad civil, MoveOn.org también realiza comunicaciones con sus usuarios vía email, por ejemplo, enviando propuestas que a estos les puede interesar para dar su apoyo (Eaton, 2010).

Brisol y Kingston, que cuentan con un sistema de presentación y administración electrónica de peticiones similar, y con influencia del sistema escocés, publican en sendas webs un informe detallado de los apoyos de la propuesta y los debates realizados en torno a esta (Whyte et al., 2005). Además, la petición puede ser presentada ante los miembros del Ayuntamiento en un encuentro con los ciudadanos que encabezan la iniciativa, antes de que se tome una decisión definitiva.

Durante el proceso, en estas ciudades inglesas, eDemocracy Project y Democratic Services, personal técnico de los respectivos ayuntamientos, son los responsables de contactar con los peticionarios desde el inicio de la petición (Whyte et al., 2005). Asimismo, en el caso particular de Kingston, se proporciona adicionalmente un 
servicio email para recibir las actualizaciones y conocimiento sobre las propuestas (Panagiotopoulos \& Al-Debei, 2010).

En el Parlamento de Escocia, por su parte, el Public Petitions Committee publica un completo informe sobre el status de la petición, con las actas de las reuniones, los documentos desarrollados a partir de estas, etc. (Lindner \& Riehm, 2011). Estos nueve miembros, seleccionados en proporción a la representación parlamentaria de cada partido, también se reúnen quincenalmente para considerar los asuntos sobre los que versan las peticiones y estudiar las medidas posibles respecto a estos (Palmieri, 2008).

Lindner \& Riehm (2011) consideran que la política de información escocesa es una de las que más contribuyen a crear mayor transparencia en el procedimiento. Y, como indican Della Porta \& Mosca (2009), este factor es una condición sine qua non para que estas plataformas sean útiles y efectivas. Macintosh et al. (2002) recuerdan que no solo es importante conseguir la verificación de las firmas, sino que todos los usuarios posibles participen. Las Naciones Unidas (2014) han apuntado a la desigualdad social como una causa intrínseca de la brecha digital en los países con un amplio desarrollo de las telecomunicaciones: en estos casos, el Gobierno ha de velar por su uso en colectivos vulnerables o desfavorecidos, como puede ser la tercera edad o quienes cuentan con diversidades funcionales.

En el caso concreto de las e-petitions, la inclusión de todos los ciudadanos en la acción política tiene como fin la representación de las minorías en las propuestas enviadas a las instituciones públicas (Whyte et al., 2005). Algunos estudios han descrito, sin embargo, la existencia de dicha brecha digital en el uso de plataformas online, que cuentan con un mayor número de usuarios con estudios superiores y trabajo mejor remunerado (Toland, 2011), son de edad joven o madura (Finnimore, 2008), viven en zonas urbanizadas con mayor población (Tomkova, 2009) o pertenecen mayoritariamente al género masculino (Cruickshank \& Smith, 2009).

Para Chadwick (2007), la facilidad de uso de una web permite superar la brecha digital entre los ciudadanos con habilidades desiguales en la utilización de las herramientas digitales. Así, la legislación que regule la solución a la brecha digital estará vinculada tanto a la garantía de acceso a un Internet universal como a la adopción de programas para la alfabetización digital (Cotino Hueso, 2011). Por su parte, las peticiones online han resuelto la mejora de su usabilidad con la previsión de información complementaria mediante la cual se instruya a los usuarios en la participación en estas plataformas (Della Porta \& Mosca, 2009). La página del Parlamento Escocés, por ejemplo, cuenta con una guía titulada How to submit a public petition a tales efectos (Maer, 2010).

El Ayuntamiento de Kingston ofrece un sumario donde explica el proceso completo de creación y gestión de peticiones mediante un formato de Frequently Asked Questions, mientras que el de Bristol cuenta con una guía que ha sido criticada por expresarse en un lenguaje demasiado técnico y formal para el usuario medio que quiera informarse sobre la herramienta de e-petitions en su localidad (Whyte et al., 2005). También el Parlamento de Queensland tiene un manual con directrices sobre cómo subir una petición, administrarla y participar del feedback para con esta (Finnimore, 2008).

Como última característica, cabe señalar la previsión por parte de estas webs de peticiones de ambientes deliberativos; esto es, de plataformas que permitan la publicación de comentarios y el debate entre los usuarios, emplazadas dentro de 
las propias páginas de las e-petitions como otra forma de participación online (Cruickshank et al., 2010). Para Tomkova (2009), la adición de estos foros permite a los internautas, ya sean ciudadanos corrientes, políticos o expertos, debatir sin restricciones de tiempo ni espacio, aunque ello no garantice un debate de calidad sobre los asuntos que se tratan.

Chadwick (2008) señala que la disposición de herramientas para la discusión colectiva en los medios sociales es un factor esencial en su popularidad. Manosevitch et al. (2014), además, estiman que existe una mayor probabilidad de que los internautas deliberen sobre asuntos sociales, económicos o políticos si se prevé un contexto previo, el cual centralice el debate, como sucedería en el caso de que cada petición dispusiera de la posibilidad de recibir comentarios.

El Parlamento Escocés y Alemán incluyen foros de discusión online para tratar temas relacionados con las peticiones que se llevan a cabo en sus páginas (Palmieri, 2008). La opción de publicación de comentarios, no incluida en el caso de Queensland, ha generado problemas por el contenido inapropiado publicado por los usuarios que, en ocasiones, tampoco se encuentra relacionado con los asuntos políticos, sociales o económicos sobre los que trata la petición en particular (Lindner \& Riehm, 2011). En Bristol, el inconveniente del servicio de discusión se relaciona con la usabilidad de la página, ya que este no es visible cuando se está visitando la petición (Whyte et al., 2005).

Para Lindner \& Riehm (2011) estos espacios de deliberación deberían servir para mejorar el vínculo de debate entre políticos y ciudadanos; sin embargo, los argumentos de estos segundos a través de los foros no se han canalizado hacia los destinatarios de las peticiones. Por lo tanto, consideran que aún existe un camino que transitar para que estos mensajes entren en juego en la toma de decisiones sobre las propuestas de los ciudadanos y permitan así una mayor implicación de estos con la política y los asuntos públicos en general.

\section{Metodología}

Este artículo cuenta con el objetivo de realizar un primer estudio de las plataformas de petición electrónica en el contexto español, y de esta forma: a) definir el funcionamiento de la plataforma Change.org y b) confrontar sus rasgos formales con los de las plataformas estatales extranjeras, a fin de comprobar cuáles de estos son análogos y cuáles aparecen solamente en uno u otro tipo de iniciativa.

Por tanto, desde lo que Velázquez \& Del Río (2005) denominan perspectiva prospectiva, esperamos analizar a partir de los resultados obtenidos el alcance de la participación política a través de la firma electrónica en España y los límites y posibilidades de las plataformas de peticiones gestionadas de forma privada. En base a esto, realizaremos recomendaciones sobre las características con las que podría contar una herramienta de e-peticiones pública en el país.

Como una limitación de este estudio, entendemos que Change, al tratarse de una compañía startup tecnológica, puede actualizarse y variar en la estructura o diseño, y alterar con ello los resultados de las variables utilizadas en el análisis. Para evitar cambios en la página durante el trabajo de campo limitaremos a tres los días de 
recogida del contenido. Así, entre el 15 y el 17 de mayo de 2015 codificamos los datos del análisis cualitativo de la página en las siguientes categorías:

- Participación: procedimiento para crear y firmar peticiones.

- Ambiente deliberativo: foros de discusión, botones sociales u otras formas de participación.

- Usabilidad: estructura de la portada y páginas concretas con peticiones, menús, secciones y mapa web con los que cuenta, motores y otras ayudas a la búsqueda.

- Feedback: posibilidades del usuario para contactar con Change.org, alguno de sus miembros o los usuarios.

\section{Resultados}

El análisis de la web de Change.org muestra resultados desiguales en relación a las características de las plataformas públicas de e-petitions. Por un lado, la página presenta un diseño sencillo, unas opciones asequibles de participación y un conjunto de instrucciones y guías que facilitan su uso. Por otro, la veracidad de las firmas, los espacios de deliberación y las posibilidades de contacto con el equipo y usuarios de Change.org son aspectos que alejan a la página de un modelo público de herramienta de recogida de firmas online.

\subsection{Change.org propone formas de participación sencillas y rápidas}

Tanto el proceso de firma de la campaña, como el de su creación y seguimiento son fácilmente asequibles para cualquier ciudadano, tanto porque se encuentran en espacios visibles dentro de la página como porque el tiempo necesario para su consecución no es superior a varios minutos, máxime si el usuario que realiza alguna de estas actividades ha accedido previamente a su cuenta en Change.org.

El log-in se realiza mediante una ventana de acceso titulada "Entra o regístrate" con dos opciones diferentes: "Entra con Facebook" o "Entra", a través de un botón rojo que coincide con el de la identidad visual de Change. En el segundo caso, el usuario ha de rellenar el email y la contraseña antes de comenzar a participar con su perfil en este espacio. Si se decide por el botón de Facebook, este proceso es automático. Si no se encuentra registrado o no ha iniciado sesión previamente, se puede completar igualmente cualquiera de los tres procesos de firma, seguimiento y creación de la petición, pues estas actividades pueden realizarse simultáneamente al proceso de registro en Change.

El panel para la firma se encuentra en la parte derecha, en una columna secundaria donde destaca el botón de color rojo con la opción "Firma" y el título del mismo color "Firma esta petición" [figura 1]. Encima de este, en el caso de no contar con un perfil previo, se exige la siguiente información: "Nombre", "Apellidos", "Correo electrónico", "Código postal" y "Mi razón para firmar es..." (apartado opcional). El seguimiento de la petición, una vez refrendada, es automático, y las actualizaciones se remiten al correo del firmante. 


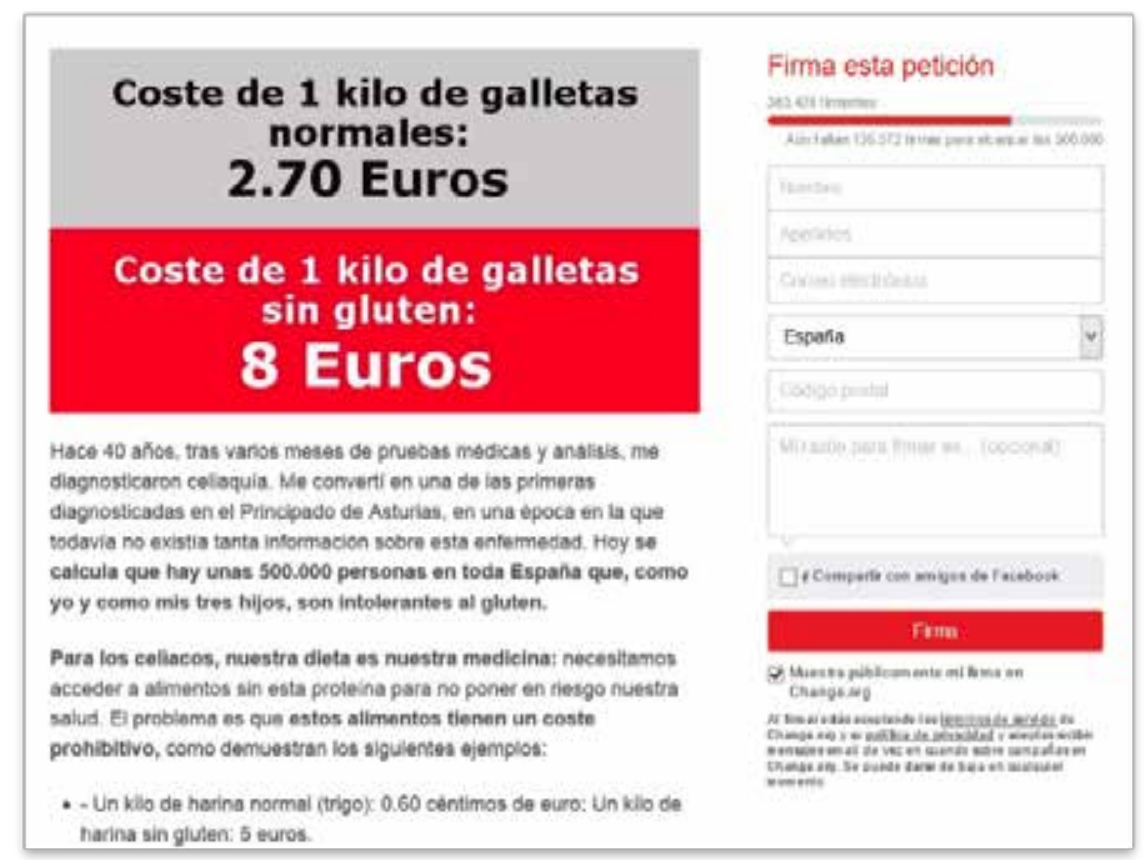

Figura 1. Formulario de firma junto al cuerpo de la petición

En cuanto a la creación de nuevas iniciativas, de la misma forma que en el caso de la firma, solamente es necesario completar un formulario, y la opción "Inicia una petición" se sitúa visible, en el menú superior. Una vez en la página de creación de las peticiones, se presenta un formulario con cuatro campos que han de completarse, a saber: “¿A quién quieres pedírselo?”, “¿Qué quieres que hagan?”, “¿Por qué es importante esta petición?" y “Añade una foto o un vídeo" (opcional). Cada opción se corresponde, respectivamente, con el destinatario de la petición, el nombre de esta, el cuerpo del texto donde se exponen los motivos que llevan a esa solicitud y una imagen para la portada.

Por tanto, Change.org dispone de un sistema sencillo para la creación de las campañas, con opciones unívocas, donde textos complementarios añadidos por la plataforma explican qué es necesario rellenar en cada apartado y aportan consejos para lograr una mayor calidad en el discurso de la iniciativa. En la misma línea, los datos solicitados para cualquiera de las formas de participación que dispone esta herramienta son escasos y, por tanto, el tiempo que se necesita para completar los formularios es mínimo, máxime en el caso del registro mediante Facebook.

La escasez de pasos para realizar cualquier tipo de actividad en Change.org, así como la claridad con la que se solicita información y las instrucciones de apoyo en cada fase de mayor dificultad convierten a la herramienta en un instrumento accesible para diversos tipos de ciudadanos que deseen ser parte de esta forma de participación en Internet. Si bien, esta misma facilidad y rapidez puede revertir en una implicación laxa por parte de los usuarios, quienes pueden decidir formar parte de ella por surelativa exigencia y no por un compromiso explícito con la causa a la 
que apoyan, problemas que autores como Morozov (2009) agruparon en el término slacktivism.

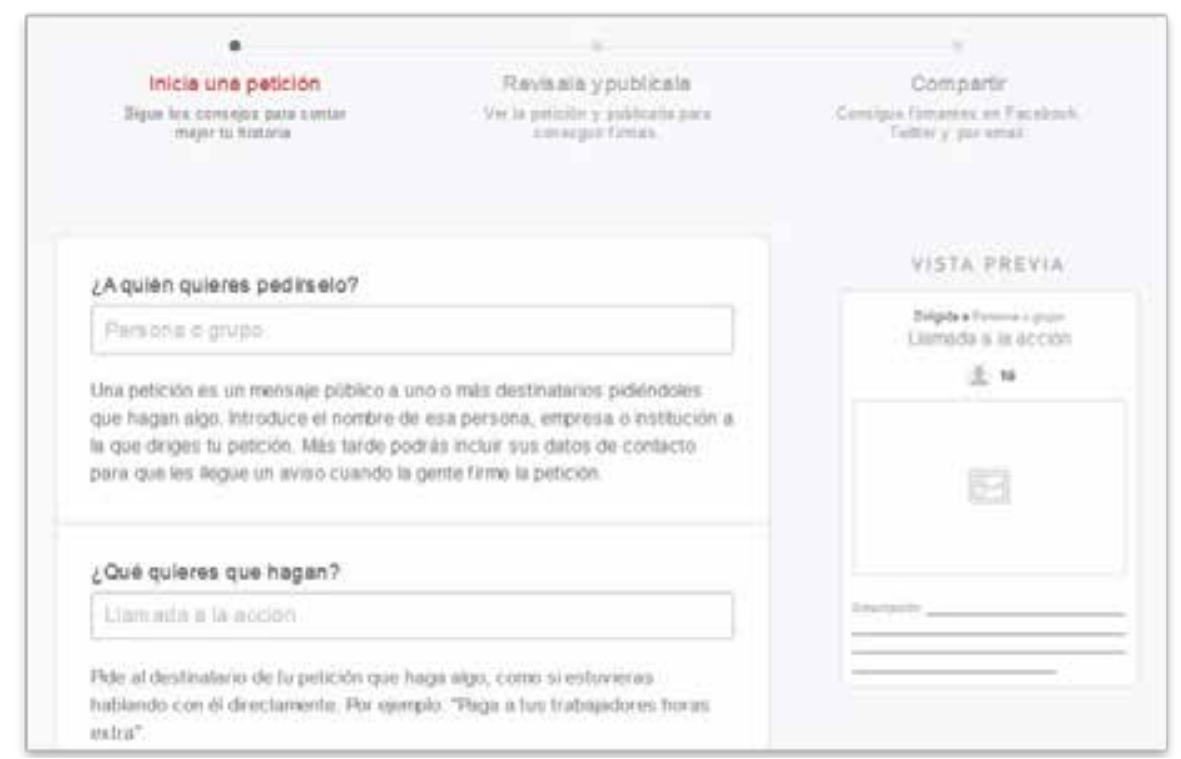

Figura 2. Página de creación de peticiones, con esquema superior, instrucciones y vista previa

\subsection{El contenido de la plataforma preferiblemente se comparte, pero no debate}

Change.org dispone de forma casi permanente en todas sus páginas la opción de hacer viral su información o mostrar el apoyo a su plataforma en las redes sociales, preferentemente en Facebook. Mientras, la posibilidad de realizar comentarios y, más aún, de debatir sobre asuntos concretos, es escasa, limitada y se encuentra en lugares específicos de la herramienta.

La escritura de mensajes en la página de cada petición individual está permitida para sus firmantes e impulsores. Por tanto, en las propuestas con victoria no se permite esta forma de participación. El texto opcional del formulario de firma escrito en "Mi razón para firmar" no aparece publicado como comentario, sino que se trata de una nota registrada en un documento con las firmas y que el creador puede descargarse desde el panel de edición de la iniciativa.

Solo una vez se ha realizado la firma, la página dispone, debajo de las actualizaciones de la petición, un cuadro de texto con el título "Razones para firmar" y el mensaje en gris “¿Por qué es importante parta ti?” (sic.). Esta frase, como en el caso de "Mi razón para firmar", está enunciando una instrucción concreta, que no es sino fomentar mensajes positivos respecto al asunto concreto que se aborda en la propuesta. En la misma línea, la condición de ofrecer el apoyo a la petición antes de 
poder contribuir al debate filtra el tipo de usuarios que participan del diálogo, y lo limita a aquellos que se encuentran a favor de lo que se expone en la iniciativa.

Una vez dentro de una petición particular, el formulario de firma ofrece la opción de compartir la iniciativa en Facebook. En el caso de seleccionarla, se genera un post específico con la propuesta y un enunciado donde se señala que ese perfil "Acaba de firmar esta petición en Change.org". Asimismo, una vez apoyada la petición, y ya de nuevo en la página principal de la propuesta, el formulario de firma se sustituye por un panel con el texto "Comparte esta petición", con un botón principal de Facebook con cuadro de texto y dos iconos debajo para utilizar Twitter o email.

Así, la plataforma ofrece un número amplio y constante de opciones para contribuir a que las peticiones concretas, así como la propia página de Change.org, se puedan convertir en contenidos virales. Se ofrece una especial atención a Facebook, tanto por su permanencia en varios espacios de la página como por los botones destacados en tamaño y color. Además, en línea con la posibilidad de crear una cuenta mediante esta red social para operar en Change.org, también es la responsable de disponer espacios de diálogo en cada una de las actualizaciones de las propuestas.

El debate no es, en cualquier caso, un factor desarrollado de forma amplia en esta plataforma. Además de la establecida por Facebook, solamente se habilita una herramienta para conversar, que se restringe a los firmantes de la petición, con una pregunta que condiciona el mensaje que se va a escribir y la opción "Me gusta" como una única posibilidad para interactuar con otros comentaristas. Esta estructura puede provocar la fragmentación del mensaje; esto es, la conversación entre grupos afines ideológicamente, que refuerzan su punto de vista y no se encuentran con opiniones disidentes (Dahlberg, 2007), lo que no contribuye a la discusión de calidad entre ciudadanos sobre los asuntos políticos, sociales y económicos que abordan las peticiones de la página.

\subsection{Existen guías de diseño y una carencia de herramientas de búsqueda}

La facilidad de navegación por Change.org se puede considerar uno de los factores más destacables de la plataforma, tanto por la accesibilidad de las explicaciones que dispone en las secciones del menú inferior como por el diseño íntegro de la web, como ya se ha indicado en el caso, por ejemplo, de los escasos pasos y múltiples consejos para la creación de una petición. No obstante, se han observado limitaciones relacionadas con la recuperación de información, ya sea sobre peticiones concretas o sobre los propios usuarios, firmantes o impulsores de campañas.

Así, la estructura de la página principal es sencilla, con una columna principal donde se disponen las iniciativas de la categoría "Destacadas". Por tanto, las peticiones así consideradas, ya se encuentren activas o cerradas con victoria, son las que se resalta y promociona. En la parte superior de la página, un menú horizontal en blanco cuenta con el logo de Change.org, que se trata de un hipervínculo para regresar a la página de inicio, las opciones "Iniciar una petición" y "Más peticiones" y el acceso, en el extremo derecho, al perfil del usuario.

En la parte inferior de la página se encuentra un segundo menú que incluye las opciones "Sobre Change.org, Blog, Empleo, Guías, Ayuda, Prensa, Anúnciate, "Desarrolladores", "Privacidad", "Términos", "Legal" y "Normas sobre anuncios". Al extremo derecho aparece la lengüeta para la selección de idioma y, por tanto, la región 
desde la que se están visitando, creando y firmando las peticiones. Ambos menús se sitúan de forma permanente en cualquier página en la cual se esté navegando, por lo que el acceso a las opciones que proponen es directo desde amplio número de espacios. Asimismo, el nombre de cada epígrafe o sección se relaciona directamente con el contenido al que remite.

La página de peticiones concretas, por su parte, cuenta igualmente con un diseño simple: el cuerpo principal de esta lo ocupa la iniciativa en sí, y tras ella sus actualizaciones y el debate de los usuarios. A la derecha, en una columna secundaria, el formulario de firma diseñado en color rojo es identificable a primera vista. La escritura de mensajes en "Razones para firmar" puede producir confusión, pues la opción de publicar un comentario solamente está disponible después de apoyar la campaña, aunque esto no se indique en ningún caso.

Para acceder a las iniciativas es necesario buscarlas en "Más peticiones", del menú horizontal. Cabe señalar que en este archivo se pueden visitar las propuestas etiquetadas como "Destacadas", "Populares" - con la clasificación secundaria "Hoy", "Esta Semana", "Desde siempre"- y "Recientes", pero no las categorizadas como "Victoria", ya sean "Destacadas" o "Recientes" [figura 3].

Así, es la propia plataforma quien decide qué petición y en qué lugar se encuentra dentro de "Destacadas", "Populares" y "Recientes", pues en este último caso tampoco hay consignas que expliquen cuándo una petición ya es lo suficientemente longeva como para desaparecer de esta clasificación. Y en el caso de que en "Recientes" exista un límite temporalparaqueunapropuestaseencuentreenesacategoríayeneseperiodo,ylainiciativa no haya conseguido ser una petición popular o destacada, cabe preguntarse si desaparece del archivo, y a partir de entonces solo es posible accederse a ella mediante su URL.

\section{Victorias}

Los miombros de Change org ganari cada dia campañas para ol cambio social creadas por personas como ta

\section{Destacasas Rinciantes}

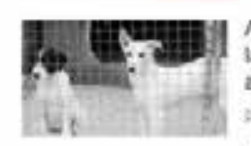

Ayuntarnionto de Oviodo codan la gestión de

la perrera municipal a protectoras de

animales

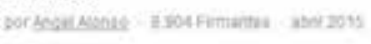

at Por fin le herras conseguida mit La penma to conato

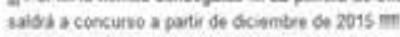
MUCHAS GRACLAS A TOOOS LOS QUE HAEES FIAUADO, CONPATTOOY APOYADO ESTO $\mathrm{m}$ GRACUS A VOSOTROS LOS NaUNES DE UA PERRERA DE ONIEDO JENDRNI UN DESTWO MESOR हा

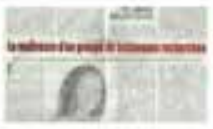

La camerunesa Christelle Nangnou. perseguida por ser lesbiana, se queda en Espana HasiloparaChristel

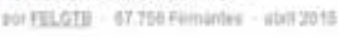

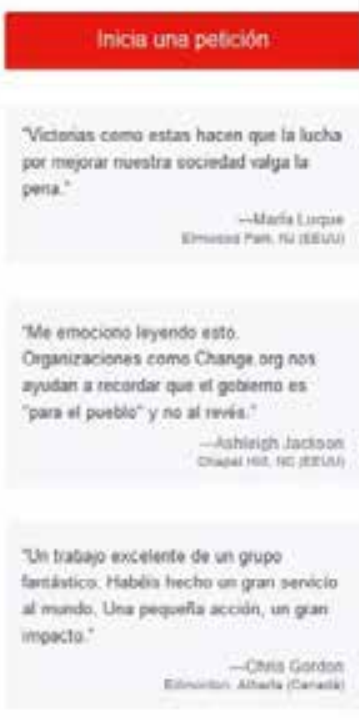

Figura 3. Fragmento del archivo de peticiones victoriosas 
El bajo nivel de usabilidad que provoca la carencia de opciones para la recuperación de contenido contrasta con el adecuado tutorial que presenta la página en la sección "Guías y consejos del menú inferior. Esta es la versión en español de la página Tips $\&$ Guides que se ofrece al usuario en el panel de edición, como se apuntaba en líneas anteriores. Se trata de un tutorial extenso, pero sintetizado y clasificado, por lo que resulta de lectura fácil. La página no se centra tanto en ofrecer instrucciones sobre los pasos que se han de seguir para firmar o crear una petición y ofrece así dos epígrafes:

- "Guías y consejos" dentro del cual se encuentran las sub-secciones "¿Cómo funciona una petición?", "Paso 1: Crea tu petición", "Paso 2: Difunde tu petición", "Paso 3: Habla con el destinatario(s) de tu petición".

- "Consejos avanzados" con las sub-secciones "Conversa con tus firmantes y haz crecer tu petición", "Envía la historia a los medios", "Construye una conversación en las redes sociales". "Entrega tu petición en persona" y "Organiza un "día de llamadas telefónicas".

Así, Change propone una serie de recomendaciones divididas por nivel de dificultad y que, en buena medida, están reconociendo implícitamente la importancia de complementar las peticiones creadas en su plataforma con muchas otras acciones externas a ella determinantes para el éxito de la propuesta, la cual no tiene asegurada una victoria por estar, simplemente, publicada en esta plataforma de recogida de firmas. Así, en "¿Cómo funciona una petición?" se añade el epígrafe "Qué tienen en común las peticiones que tienen éxito, con los ítems: "El objetivo es convincente y puede conseguirse", "La petición incluye el correo electrónico del destinatario", "Las redes sociales sirven para difundir tu petición y conseguir más apoyos y, a una petición online le sigue la acción offline".

En definitiva, toda la información incluida en "Guías y consejos", además de relevante, cuenta con un diseño agradable para la lectura. En este sentido, la longitud de los textos es apropiada, suficiente para informar convenientemente al usuario sin convertir la lectura en una actividad tan tediosa que se deseche antes de su finalización. La inclusión de cuadros grises con ejemplos prácticos de las instrucciones que ofrecen en esta sección son elementos útiles para explicar con sencillez los procesos que se han de llevar a cabo para que los usuarios puedan hacer de su petición una victoria.

De forma general, todas las secciones publicadas en Change.org mantienen una distribución ordenada de la información que publican. La utilización de la negrita, la numeración y las viñetas, así como links azules para la navegación dentro de la misma página y la inclusión de imágenes e iconos en esta facilitan la lectura. El lenguaje utilizado no es técnico, sino sencillo y redactado con expresiones cotidianas y cercanas a cualquier usuario [figura 4].

Asimismo, y a lo largo de todo el sitio web, la combinación del texto negro o gris sobre el fondo blanco hace sencilla la navegación por la página. El contraste con el color rojo que aparece, por ejemplo, en los botones de creación de la petición o en los formularios de firma sirve para destacar la información más relevante y para invitar a la participación a los visitantes de la página. 


\section{Guías y Consejos}

\section{Cambia tu barrio y tu mundo}

Cada dia, persorias como tà usan Change erg para consegair cambios males m los ternas que les prescupan. Si queres mais información puedes leer el apartado sobre como funcions una paticion aniru $r$ si gqaeres lanzarta a crear tu peticion puedes leen algunos sencilios consejos aqui

\section{Paso 1: Crea tu petición online}

Paso 2: Promueve tu petición

* Paso 3: Habla con el destinatario de tu petición

¿Quieres saber mas? Aqui tienes algunos consejos avantados:

Engancha y aumenta ol nârsero de

personas que te apoyan

Cerno mantener a tus fimintes inducradas

a medida que tu cariparla cance

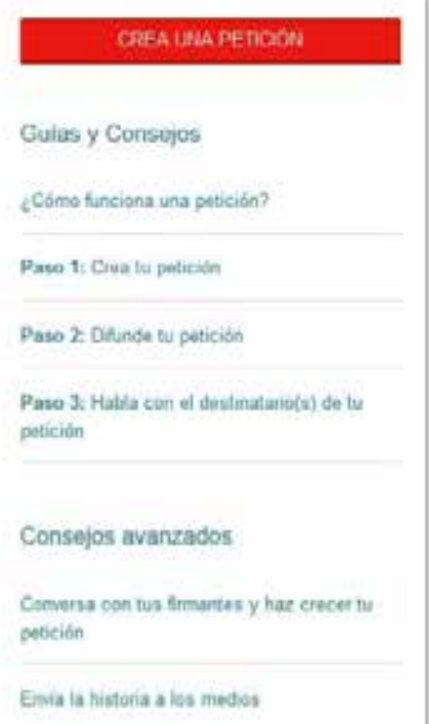

Figura 4. Fragmento de la sección "Guías y consejos"

En definitiva, tanto el diseño de la página como el lenguaje utilizado para acercarse al usuario facilitan la lectura de sus textos y hacen más atractiva la navegación y estancia en Change.org. La sección "Guías y consejos" ofrece un amplio conjunto de recomendaciones para que cualquier usuario pueda promocionar su petición de la forma más efectiva posible. Sin embargo, la plataforma no ofrece facilidades para la búsqueda de contenido en su página, incluidas las peticiones. Solo un conjunto de propuestas, las que aparecen en portada y las primeras dispuestas en los archivos, son visibilizadas por la plataforma y, por tanto, susceptibles de ser firmadas. Un fácil acceso a toda la oferta de peticiones contribuiría sin duda al apoyo de esas propuestas, de la misma forma que lo hace la inclusión de tutoriales.

\subsection{Muchas posibilidades permiten el contacto con la prensa y pocas con los usuarios}

De la misma forma que el menú principal dispone de un número adecuado de opciones en las que se puede visitar de forma directa buena parte de la información de Change.org, ninguno de los menús incluye una sección dedicada a disponer todas las formas de contacto posible con la plataforma, con emails específicos para las consultas de diferente tipo, ya sean de ámbito legal, por ejemplo, o las relativas al funcionamiento de la plataforma. Ello contrasta con la disposición de varias posibilidades para el envío de correos electrónicos por parte de los periodistas, dentro de la sección "Prensa".

Así, existen direcciones postales y otras formas de contacto distribuidas a lo largo de los textos de las diferentes secciones del menú inferior. "Política de cookies", 
"Política de privacidad y Términos servicios ofrecen la posibilidad de enviar cartas a diferentes departamentos localizados en San Francisco (California). En esta última sección se añade también un número de teléfono, un número de fax y un correo electrónico para el contacto con Change en relación a problemas de violación de derechos de autor. No apreciamos ningún tipo de información más respectiva a la comunicación con la plataforma en estas secciones por lo que esta es escasa además de poco accesible, al integrarse en textos y no contar con sección particular.

Además, la opción "Ayuda" remite al Centro de asistencia de Change (Help Center, http://help.change.org/home), gestionado desde Estados Unidos, cuyo enlace también está presente en las secciones mencionadas anteriormente y en otras como "Sobre las firmas" o "Modelo de negocio". Este espacio, además de contar con las "Preguntas Frecuentes» de los usuarios, incluye un formulario de contacto. Entre los datos que este solicita se encuentran la especificación sobre el perfil que envía el mensaje (creador de una petición, destinatario, firmante o periodista), el sistema operativo del ordenador y navegador de Internet desde el cual se envía la duda. Además, se da la opción de agregar un archivo adjunto.

Si bien este Centro de asistencia es un espacio favorable tanto para el contacto con la plataforma como para mejorar su usabilidad, lo cierto es que este formulario también podría integrarse en la propia página de Change.org. Además, para iniciar sesión en este apartado es necesario registrarse con una cuenta específica, que puede ser creada o bien por correo electrónico o por Facebook y, en este caso, también Twitter.

Aunque los periodistas pueden enviar también un formulario a través de esta plataforma, la sección de "Prensa" les ofrece varios emails a los cuales recurrir, y que se pueden encontrar en diferentes sub-secciones de este apartado. Así, en "Departamento de Prensa y Comunicación de Change.org" se señala en dos ocasiones el email para medios y al hacer click en "Regístrate para recibir notas de prensa" se autogenera un correo electrónico con el asunto [Registración de notificaciones]", dirigido a la misma dirección. Además, el "Dossier de prensa", incluye el nombre de los dos responsables de comunicación en España con su contacto correspondiente.

Cabe señalar que un usuario común solo puede contactar de forma directa con los miembros de Change en el caso de que estos le agreguen como amigos en la plataforma, a través de "Nuestro equipo". Por extensión, para ello es necesario contar primero con un perfil individual y más tarde enviar la solicitud de amistad. Una vez el otro usuario la acepta, se puede acudir a la opción "Redactar un mensaje" en "Buzón", dentro de la cuenta del usuario, desde donde se ha de seleccionar el destinatario entre el conjunto de contactos que tenga cada cuenta [figura 5].

El mismo proceso es necesario para contactar con el resto de usuarios de Change, ya sean peticionarios o firmantes. El nombre de estos primeros y un enlace a su perfil aparece en la iniciativa concreta que ha publicado. En el caso de los segundos no siempre es posible conocer si han apoyado o no una campaña concreta, ya que estas no son públicas.

La única forma de conocer a este tipo de usuario es revisar la herramienta "Razones para firmar» y consultar a los comentaristas, ya que previamente han apoyado la petición. Los mensajes situados en las actualizaciones muestran también a sus autores, si bien estos no necesariamente hayan tenido que dar su firma para escribir en las novedades. Tampoco es posible encontrar a un usuario concreto en la 
plataforma, pues, como se señalaba anteriormente, no existe este tipo de ayuda a la búsqueda.

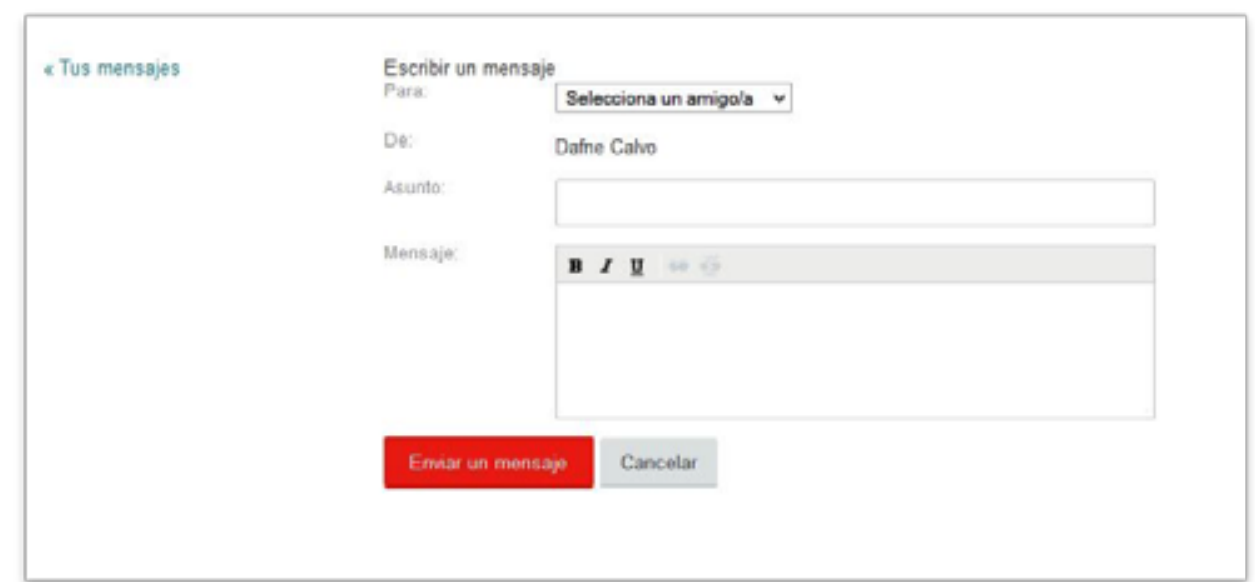

Figura 5. Buzón dispuesto en la cuenta de Change

En cuanto a la comunicación con la personalidad o institución a quien se dirige la propuesta, la página de la petición no dispone ninguna forma de contacto pública para todos los visitantes o firmantes de la iniciativa. En "Habla con el destinatario(s) de tu petición» de la sección "Guías y consejos" explican la importancia casi indispensable de contactar con la persona o institución a la que va dirigida la iniciativa. Por otra parte, Change en España se encuentra desarrollando una funcionalidad llamada Decision Makers (https://www.change.org/es/decision-makers), para los destinatarios de las peticiones de la plataforma, al que pertenecen Albert Rivera, BBVA o el Ayuntamiento de Barcelona.

Se puede considerar que Change.org es una plataforma que ofrece pocas posibilidades de contacto con los responsables de la plataforma, así como con los usuarios, y de forma general es el propio equipo quien se comunica con usuarios específicos para ayudarlos con sus campañas. Esto último, además, puede ir en detrimento de las propias peticiones, pues su creador no dispone de una forma sencilla y directa de hablar con los apoyos de su iniciativa y con ello comprometerlos en mayor medida por la causa.

$\mathrm{Si}$ bien es cierto que cuenta con el Centro de asistencia, que permite realizar consultas a los usuarios, el resto de contactos que propone Change.org en su propia página o bien son correos electrónicos centrales, válidos para todos los países, o bien son otras formas de comunicación más costosas en tiempo y dinero, sobre todo para alguien que vive en España y ha de llamar o enviar un escrito por correo postal a Estados Unidos.

Estas escasas posibilidades que se ofrece al usuario contrastan con las que se presentan a la prensa que, además de poder comunicarse desde el formulario del Centro de ayuda, disponen de tres emails corporativos dirigidos a contactos españoles, lo que da buena cuenta de la importancia que la página otorga a su aparición en los 
medios. Se trata, por tanto, de una estrategia de comunicación más elitista, tendente a buscar vínculos con los generadores de información, pero no con los usuarios.

\section{Discusión de los resultados y conclusiones}

Este trabajo ha pretendido aproximarse al estudio de las plataformas de petición electrónica como una forma de participación política digital, y a su vez ha tratado de enmarcar el estudio en el debate sobre las empresas privadas que en la actualidad funcionan como canalizadores de los procesos democráticos que los Estados no facilitan a sus electores.

Los resultados obtenidos nos permiten realizar una contribución al debate sobre las implicaciones que las plataformas digitales tienen en la forma en la que los ciudadanos participan de los procesos políticos de un sistema democrático concreto, en este caso el español. Estos guardan relación con factores internos a la página, como puede ser su estructura y características formales, abordadas en esta investigación.

Si Change.org se equipara con las plataformas de e-petitions gestionadas por las administraciones públicas de países anglosajones y europeos, se pueden observar varias diferencias que no necesariamente se encuentran siempre en detrimento de la alternativa privada. La página cuenta con un diseño agradable y de lectura fácil, y no incurre en errores que se han indicado en las herramientas públicas. Así, por ejemplo, el lenguaje utilizado en todas las instrucciones e informaciones ofrecidas es sencillo, y se aleja de tecnicismos que impidan al usuario medio informarse sobre la herramienta, como sucede en el Ayuntamiento de Bristol (Whyte et al., 2005).

La usabilidad es una de las características más positivas que se han registrado en torno a Change.org, a pesar de la falta de herramientas para la recuperación de informaciones. Además de contar con un diseño agradable, que facilita la lectura y los procesos de participación $\square$ desde los más sencillos, como la firma, hasta los más complejos, como es la creación de una petición $\square$, estos se encuentran simplificados y su consecución no supone ningún conocimiento técnico especializado. Si bien ello puede revertir, como se ha señalado anteriormente, en una acción política de bajo nivel de esfuerzo o activismo vago (Morozov, 2009), también supone una superación de la brecha digital.

Sin embargo, aunque el discurso de Change trata sobre el empoderamiento ciudadano, no señala que este se cumpla de forma sencilla y, de hecho, en "Guías y consejos" se recomienda una serie de estrategias que se han de seguir para poder obtener los resultados esperados. Por tanto, la victoria en Change supone un compromiso y grado de esfuerzo mayor que el proceso de firma o creación de una petición, y que se exige acciones fuera de la propia plataforma e incluso del ecosistema digital, como podría ser la reunión con funcionarios electos o la protesta offline.

Además, algunos fragmentos de la página se encuentran escritos en inglés, como los datos sobre los colectivos que publican peticiones en la página, muestra del lugar de procedencia de Change y que dificulta la comprensión de quien no conozca el idioma. Este hecho es poco probable en plataformas públicas de un solo país, donde esta es capaz de adaptarse de forma completa a las idiosincrasias de este, incluida la utilización exclusiva de sus lenguas oficiales. 
Un mayor número de ciudadanos participando es beneficioso para la plataforma, pero también para la propia sociedad española si ello supone que las campañas gestionadas en esta página sean mucho más representativas si de ellas no se encuentran excluidos ciudadanos con menor capacidad para la utilización de herramientas digitales, como pueden ser los usuarios con menor nivel educativo, cultural y económico, quienes viven en zonas rurales o quienes cuentan con mayor edad (Toland, 2011; Finnimore, 2008; Tomkova, 2009). Que estos colectivos puedan formar parte de procesos políticos y comprender en qué consisten, así como qué supone su navegación por el sitio puede contribuir positivamente a lo que Cotino Hueso (2011) denomina "alfabetización digital".

El asesoramiento directo a los peticionarios, además, es específico para peticiones concretas, aquellas que experimentan un crecimiento amplio en un periodo corto de tiempo. Aunque "Guías y consejos" ofrece un amplio número de recomendaciones para la mejora de la petición, este no es suficiente para conseguir que el usuario tenga con asesoramiento completo en la página, pues las formas de contacto con los responsables de esta, incluso con otros usuarios que pudieran aportar una mayor experiencia, son escasas y más complejas de realizar.

A ello es necesario añadir las escasas formas de contacto que existen en la plataforma, algunas de las cuales además remiten al extranjero, un hecho que, de nuevo, no es previsible en el caso de plataformas públicas exclusivas de un país. Por otro lado, la aplicación Decision Makers, aún en desarrollo, demuestra la debilidad de Change para ofrecer un contacto directo con las Administraciones españolas, a pesar de que el feedback es uno de los factores esenciales en la efectividad de las plataformas para la participación política, que en el caso de las opciones administradas por los poderes públicos sí está garantizado (Lindner \& Riehm, 2011).

A pesar de estas conclusiones, como adelantamos en el apartado metodológico sobre las limitaciones de este trabajo, hemos apreciado cambios en la página tras el registro cualitativo: el Centro de asistencia ha renovado su diseño. Pero la modificación más notable ha sido la adición de un buscador a la página principal, una herramienta cuya codificación hubiera influenciado en los resultados obtenidos en la categoría de usabilidad.

Este hecho, lejos de limitar el estudio de las peticiones electrónicas en España, abre nuevas vías de investigación. En este sentido, resulta interesante realizar un seguimiento de la plataforma Change.org, a fin de observar, en cada nueva actualización del servicio, la evolución de esta forma de participación en Internet, y así diagnosticar qué factores presentan mejores cualidades para que los ciudadanos debatan y sean parte de estos procesos de participación política a través de la reivindicación de cuestiones concretas con los poderes públicos.

En definitiva, y de forma general, cabe preguntarse si este mecanismo de toma de decisiones sobre asuntos políticos, económicos o sociales se encuentra emulando las características de la actividad de los ciudadanos enmarcada dentro del tradicional derecho de petición o, sin embargo, si su traslado al ecosistema digital supone una mejora cualitativa de las posibilidades del usuario para la representación de los electores en sus regímenes democráticos, de forma que los Estados, incluido el español, lo promuevan, ya sea a través de plataformas públicas gestionadas por ellos mismos o atendiendo a las preocupaciones que los ciudadanos publiquen en sus 
alternativas civiles, para conseguir con ello una apertura de sus sistemas políticos a toda la ciudadanía.

\section{Bibliografía}

Campos-Domínguez, E. (2014). "Historia, Concepto y Evolución del Parlamento 2.0”. En: Rubio Núñez, R. Parlamentos abiertos: tecnología y redes para la Democracia. Madrid: Congreso de los Diputados, 31-60.

Chadwick, A. (2008). Web 2.0: "New Challenges for the Study of e-Democracy in an Era of Informational Exuberance", A Journal of Law and Policy for the Information Society, vol. 5, núm. 1, 9-42.

Cotino Hueso, L. (2011). “Tratamiento jurídico y normativo de la Democracia, participación y transparencia electrónicas: presente y perspectivas”. En: Barrat I Esteve, J., \& Fernández Riviera, R. M. Derecho de sufragio y participación ciudadana a través de las nuevas tecnologías. Pamplona, 221-260.

Cruickshank, P., \& Smith, C. F. (2009). "Self-Efficacy as a Factor in the Evaluation of e-petitions". Proceedings of Edem, 223-232.

Cruickshank, P., Edelmann, N., \& Smith, C. F. (2010). "Signing an E-Petition as a Transition from Lurking to Participation". En: Jassen, M., Macintosh, A., Scholl, H. J., Tambouris, E., Wimmer, M. A., Bruijin, H., \& Tan, Y. Electronic Government and Electronic Participation. Trauner: Linz, 275-282. Doi: 10.1108/17506161211267536.

Dahlberg, L. (2007), "Rethinking the Fragmentation of the Cyberpublic: from Consensus to Contestation", New Media \& Society, vol. 9, núm. 5, 827-847.

Davis, R. (1999). "Communications Technology and Democracy". En: Davis, R. The Web of Politics: The Internet's Impact on the American Political System. Oxford: Oxford University Press, 9-40.

Diaz, C., Kosta, E., Dekeyser, H., Kohlweiss, M., \& Nigusse, G. (2009). “Privacy Preserving Electronic Petitions", Identity in The Information Society, vol. 1, núm. 1, 203-219.

Eaton,M.(2010). "Manufacturing CommunityinanOnlineActivistOrganization".Information, Communication \& Society, vol. 13, núm. 2, 174-192. Doi: 10.1080/13691180902890125.

Finnimore, S. (2008). "E-Petitions-the Queensland Experience”. Anzacatt Seminar. Hobart, Australia.

Juris, J. (2005). “The New Digital Media and Activist Networking Within Anti-Corporate Globalization Movements", The Annals of the American Academy of Political and Social Science, vol. 597, núm. 1, 189-208. Doi: 10.1177/0002716204270338.

Lindner, R., \& Riehm, U. (2009). "Electronic Petitions and Institutional Modernization", International Parliamentary E-Petition Systems in Comparative Perspective. Ejournal Of Edemocracy And Open Government, vol. 1, núm. 1, 1-11.

Lindner, R., \& Riehm, U. (2011). "Broadening Participation Through E-Petitions? An Empirical Study of Petitions to the German Parliament”, Policy \& Internet, vol. 3, núm. 1, 63-85. Doi: 10.2202/1944-2866.1083.

Macintosh, A., Malina, A., \& Farrell, S. (2002). "Digital Democracy Through Electronic Petitioning", Advances in Digital Government, núm. 26, 137-148.

Maer, L. (2010). "Proposals for an E-Petitions System for the House of Commons". Parliament and Constitution Centre, 1-23. 
Manosevitch, E., Steinfeld, N., \& Lev-On, A. (2014). "Promoting Online Deliberation Quality: Cognitive Cues Matter", Information, Communication \& Society, vol. 17, núm. 10, 1177-1195. Doi: 10.1080/1369118x.2014.899610.

Morozov, E. (2009). “The Brave New World of Slacktivism”, Foreign Policy, vol. 19, núm. 5.

Palmieri, S. A. (2008). "Petition Effectiveness: Improving Citizens' Direct Access to Parliament", Australasian Parliamentary Review, vol. 23, núm. 1, 121-135.

Panagiotopoulos, P., \& Al-Debei, M. (2010). "Engaging with Citizens Online: Understanding the Role of Epetitioning in Local Government Democracy”. Internet, Politics, Policy, $16-17$.

Toland, J. (2011). "E-Petitions in Local Government: The Case of Wellington City Council". Proc. of the C\&T 2011 Workshop on Government and Citizen Engagement. Brisbane, Australia.

Tomkova, J. (2009). "E-Consultations: New Tools for Civic Engagement or Facades for Political Correctness", European Journal of Epractice, núm. 7, 45-54.

Whyte, A., Renton, A., \& Macintosh, A. (2005). "E-Petitioning in Kingston And Bristol. Edinburgh". International Teledemocracy Centre, 1-56.Goldmann, L. (1972). Para una sociología de la novela. Madrid: Ciencia Nueva.

Jitrik, N. (1997). Historia e imaginación literaria: las posibilidades de un género. Buenos Aires: Universidad de Buenos Aires.

Lyotard, J. F. (1994) La condición postmoderna. Informe sobre el saber. Madrid: Cátedra.

López Eire, A. (2002). Retórica clásica y teoría literaria moderna. Madrid: Arcos.

Lukács, G. (1979). Teoría de la novela. Barcelona, Grijalbo.

Mittell, J. (2007). "Film and Television Narrative". En Herman, David (Ed.) The Cambridge Companion to Narrative. Nueva York: Cambridge University Press.

Mittell, J. (2013). Complex TV: The Poetics of Contemporary Television Storytelling. Pre-publication edition. MediaCommons Press. Recuperado de http://mcpress.mediacommons.org/complextelevision (Fecha de acceso: 1/5/2014).

Pérez, X. (2011). "Las edades de la serialidad”, La Balsa de la Medusa, núm. 6.

Sloterdijk, P. (2003). Crítica de la razón cínica. Madrid: Siruela.

Thompson, R. (1997). Television's Second Golden Age: From Hill Street Blues to ER. Nueva York: Syracuse University Press.

Vattimo, G. (1990). La sociedad transparente. Barcelona: Paidós.

Villegas, J. (1978). La estructura mítica del héroe. Barcelona: Planeta.

Vogler, C. (2002 [1992]). El viaje del escritor: las estructuras míticas para escritores, guionistas, dramaturgos y novelistas. Barcelona: Ma Non Troppo. 